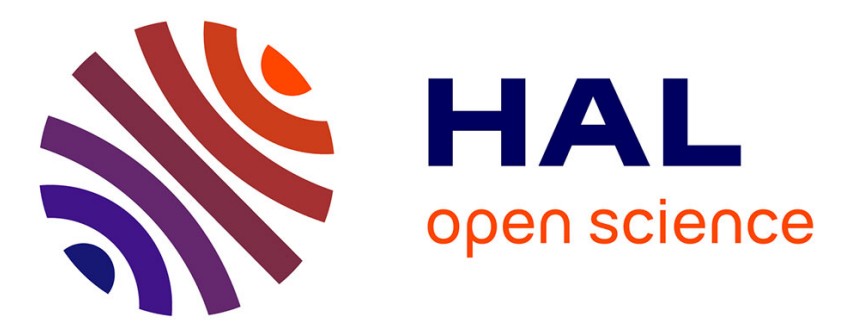

\title{
Determination of Gray Cast Iron Age Strengthening by Nondestructive Methods: Effect of Alloying Elements
}

\author{
Alexis Vaucheret, Frédéric Rossi, Jean Quesada, Eric Albertalli
}

\section{To cite this version:}

Alexis Vaucheret, Frédéric Rossi, Jean Quesada, Eric Albertalli. Determination of Gray Cast Iron Age Strengthening by Nondestructive Methods: Effect of Alloying Elements. Journal of Materials Engineering and Performance, 2019, 28 (7), pp.4026-4033. 10.1007/s11665-019-04180-2 . hal-02284432

\section{HAL Id: hal-02284432 \\ https://hal.science/hal-02284432}

Submitted on 16 Sep 2019

HAL is a multi-disciplinary open access archive for the deposit and dissemination of scientific research documents, whether they are published or not. The documents may come from teaching and research institutions in France or abroad, or from public or private research centers.
L'archive ouverte pluridisciplinaire HAL, est destinée au dépôt et à la diffusion de documents scientifiques de niveau recherche, publiés ou non, émanant des établissements d'enseignement et de recherche français ou étrangers, des laboratoires publics ou privés. 


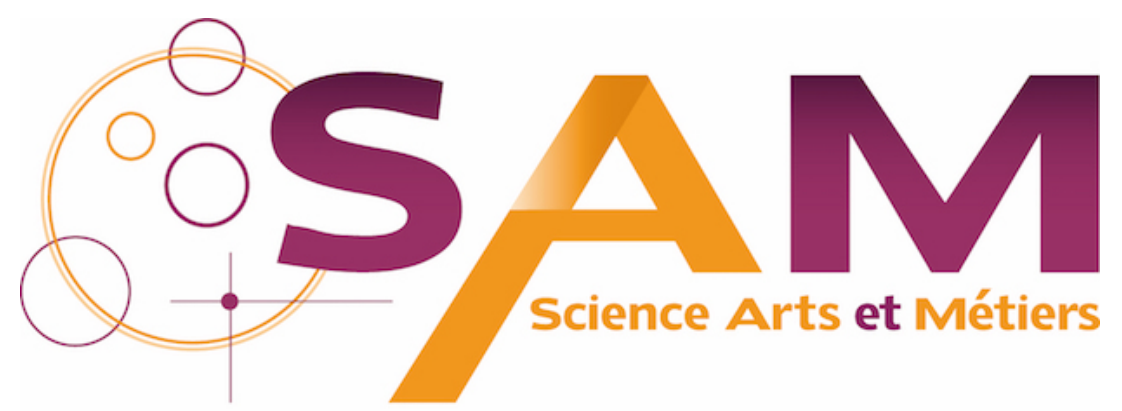

Archive Ouverte - Open Repository

\section{Science Arts \& Métiers (SAM)}

is an open access repository that collects the work of Arts et Métiers ParisTech researchers and makes it freely available over the web where possible.

This is an author-deposited version published in: https://sam.ensam.eu Handle ID: .http://hdl.handle.net/10985/16607

\section{To cite this version :}

Alexis VAUCHERET, Frédéric ROSSI, Jean QUESADA, Eric ALBERTALLI - Determination of Gray Cast Iron Age Strengthening by Nondestructive Methods: Effect of Alloying Elements Journal of Materials Engineering and Performance - Vol. 28, nº, p.4026-4033-2019 


\title{
Determination of Gray Cast Iron Age Strengthening by Nondestructive Methods: Effect of Alloying Elements
}

\author{
Vaucheret Alexis, Rossi Frédéric, Quesada Jean, Albertalli Eric
}

\begin{abstract}
Gray cast iron age strengthening is a phenomenon known as a modification of the alloy's structure by ironnitride precipitation during few days after casting. It generates an evolution of cast iron mechanical properties as a gain of hardness and Young's modulus. In a first time, this article presents the possibility to monitor the aging time and the intensity of age strengthening using two nondestructive methods: nonstandard Rockwell hardness and inert frequencies measurement. In a second time, the study shows the influence of the alloying elements on this phenomenon and particularly the influence of free nitrogen amount, which is a first-order parameter to control aging. Finally, a prediction model of the time and the intensity of age strengthening has been elaborated using the results of the two different monitoring described.
\end{abstract}

Keywords age strengthening, cast iron, casting, characterization, hardness, inert frequency, nitrogen

\section{Introduction}

This study was led in order to better understand gray cast iron age strengthening and to control it. The consequences of this phenomenon are known as a modification of cast iron mechanical properties in a short time. Nevertheless, these changes could generate some defects (excessive tool wear, vibration...) during cast iron machining in industrial conditions. For the moment, the only way to face this problem is stocking the parts for few days, until they reach their metallurgical stability.

Very few studies concern gray cast iron age strengthening; V. L. Richards and W. Nicola principally led them (Ref 1). This phenomenon mainly affects the machinability of the casting parts and their mechanical properties like ultimate tensile strength (UTS) or hardness. Richards and Nicola have followed the evolution of UTS during the aging time at room temperature. This property clearly increases during age strengthening. Moreover, the Vickers's micro-hardness in ferrite phase follows the same evolution as UTS (Ref 2). The evolution of these properties follows an Avrami kinetic behavior, that is to say a sigmoid function, as it is visible in Fig. 1.

Vaucheret Alexis, LaBoMaP, Arts et Métiers ParisTech, 71250 Cluny, France; and LabECAM, ECAM Lyon, INSA-Lyon, Université de Lyon, 69005 Lyon, France; Rossi Frédéric and Quesada Jean, LaBoMaP, Arts et Métiers ParisTech, 71250 Cluny, France; and Albertalli Eric, Renault ACI, 15 Avenue Pierre Piffault, 72000 Le Mans, France. Contact e-mail: alexis.vaucheret@ecam.fr.

In the same time, the machinability of the gray cast iron parts and their surface roughness improves with age strengthening and so the wearing of the tool decreases (Ref 1, 2). First of all, a correlation between the increase in mechanical properties and the machinability of a material does not seem evident. Generally, increasing the hardness causes faster tool degradation and reduction in the number of parts machined by tool. The correlation is due to a better chip's fragmentation caused by reducing ductility of the free ferrite and so by decreasing cast iron friction on the tool's flank wear. Some impact energy results on unaged and aged cast iron proved it by showing that age strengthening decreased the resilience of the samples (Ref 2).

These studies showed that age strengthening was caused by nitrogen in solid solution in ferrite of cast iron matrix (Ref 1-4). Nitrogen could form Guinier-Preston zones which would change into another type of precipitate structure as aging progresses. These precipitates are stable iron-nitrides $\mathrm{Fe}_{4} \mathrm{~N}$ which formation led to matrix enhancement by dislocation locking mechanism that could occur with a $\mathrm{Fe}-\mathrm{N}$ or $\mathrm{Fe}-\mathrm{C}-\mathrm{N}$ precipitate. Differential scanning calorimetry measurement in Fig. 2, between a nonaging sample and a high nitrogen specimen as references, showed this transformation. Moreover, Burgess (Ref 4) showed this nitride precipitates by neutron scattering in ferritic malleable cast iron. Also, Fig. 3 presents the linear correlation between the gain of UTS measured during age strengthening and thermodynamically modeled iron-nitride $\mathrm{Fe}_{4} \mathrm{~N}$ content (Ref 5).

Nitrogen with its diffusional mobility at room temperature could form $\mathrm{Fe}_{4} \mathrm{~N}$ nitrides responsible for age strengthening. So the influence of cast iron alloying elements is decisive on the aging time and intensity, as shown by Richards and Anish (Ref 6). Alloying elements like titanium, boron or aluminum will affect aging by reducing the amount of nitrogen in excess able to react with iron, by forming nitrides. All the elements where nitride formation enthalpy on Ellingham diagram, visible in Fig. 4, are lower than iron one will react with nitrogen before iron.

As said before, it could be possible to control gray cast iron age strengthening by using alloying elements during the melting process. Richards and Anish (Ref 6) managed to 


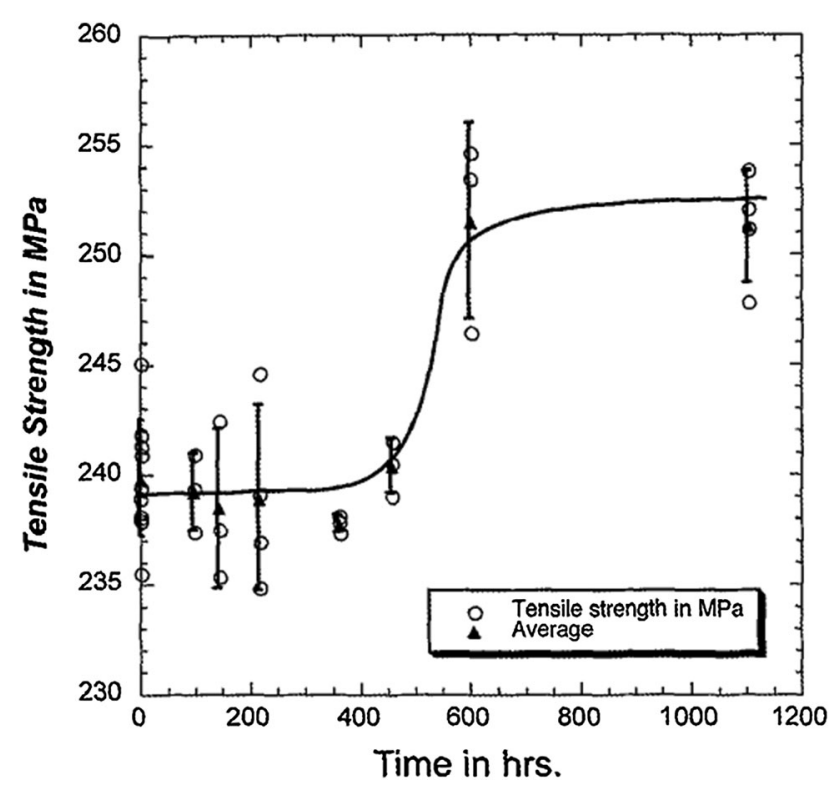

Fig. 1 Ultimate tensile strength depending on aging time maturation. The figure was reproduced from Ref 3 courtesy of IJMC

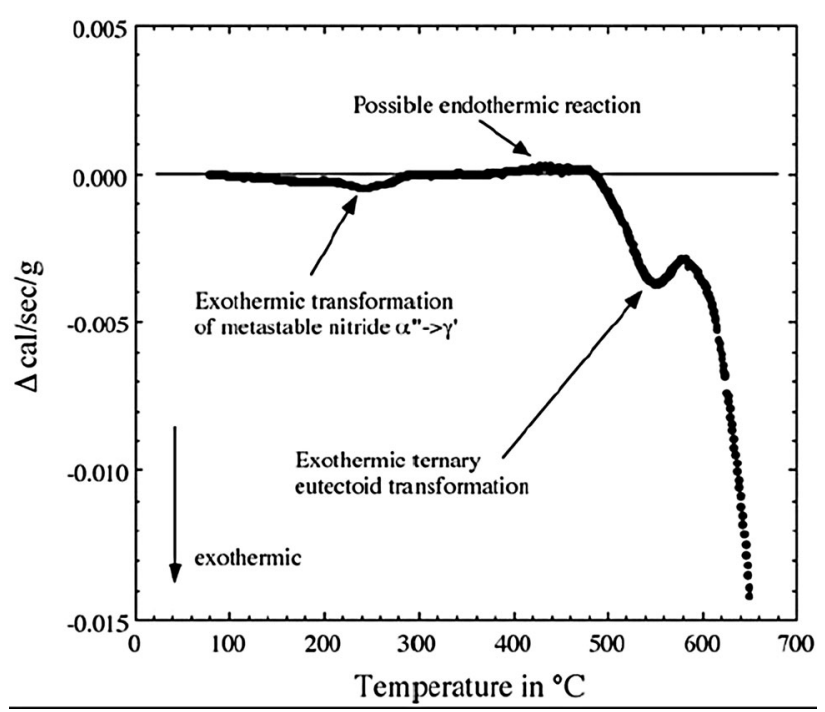

Fig. 2 DSC result of a nonaging sample and a high nitrogen specimen as references. The figure was reproduced from Ref 3 courtesy of IJMC

propose a prediction model of the gain of UTS during a 20-day period of aging based on the influence of alloying elements in cast iron:

$$
\begin{aligned}
\mathrm{UTS}_{20}-\mathrm{UTS}_{0}= & 6.07+788 * \% \mathrm{~N}-324 * \% \mathrm{Al}-173 \\
& * \% \mathrm{Ti}-390 \% \mathrm{~B}
\end{aligned}
$$

However, the model presents some restriction because it does not take into account the influence of carbon which is mainly responsible for the amount of nitrogen in solution in cast iron (Ref 8). Nevertheless, this way of aging control does not seem to be much profitable in regard of alloying elements price per tons.

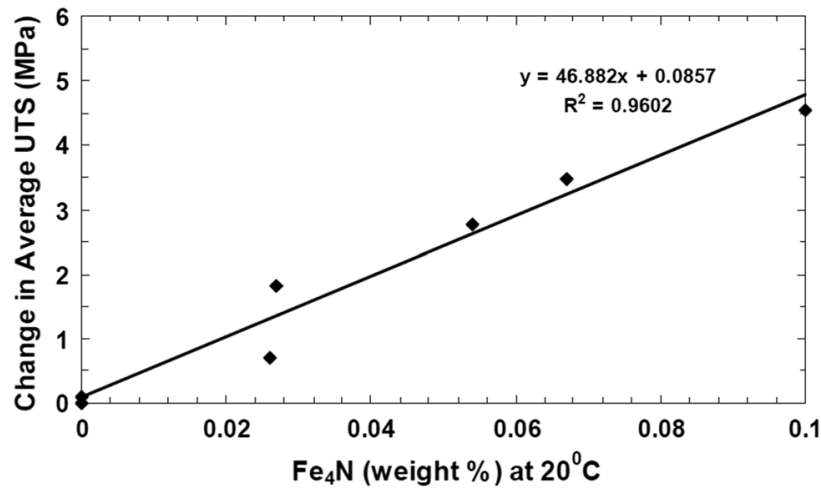

Fig. 3 Experimentally measured changes in average UTS from age strengthening as a function of thermodynamically modeled ironnitride content. The figure was reproduced from Ref 5 courtesy of IJMC

Based on Richards and Nicola' studies, this work wants to monitor cast iron age strengthening by using simple, classical and nondestructive mechanical tests and to show the influence of alloying elements on this phenomenon.

In a first time, the aim of this study is to find a method to observe aging directly on casting parts without machining any specific samples, contrary to the tensile test. The purpose of this work is to characterize the aging directly on raw parts as much as possible and so minimize the use of machining. In a second time, this article will show the influence of alloying elements on cast iron age strengthening and the possibility to control it directly by variations of cast iron chemical composition.

The next paragraph "Materials and Methods" presents the different methods of monitoring gray cast iron age strengthening by nondestructive methods: Rockwell hardness and inherent frequencies. The experimental process of addition of alloying elements in cast iron will also be described in this part. The third paragraph will present and discuss the results of this study: the monitoring of age strengthening by nondestructive method and the influence of alloying elements and most particularly nitrogen.

\section{Materials and Methods}

\subsection{Rockwell Hardness}

First of all, hardness could not be considered as a nondestructive method as tomography for example. In fact, it is a semi-destructive method due to the permanent deformation caused by the indentor. In case of casted parts, a specific localization on a nonfunctional surface is often designed for hardness test. The deformation caused by hardness testing will neither affect the properties of the parts, nor it service time. The parts could be used normally after testing. It is why hardness can be considered in this study as a nondestructive method.

As shown in past research, micro-hardness of cast iron ferritic matrix increases with aging $(\operatorname{Ref} 1,2)$. This study wants to correlate the aging with macro-hardness of the parts. The first thing was to select the appropriate type of hardness. For this, the heterogeneity of the material between the matrix and the flake graphite makes it necessary to use a spherical penetrator to obtain an average value of the hardness. Then, some 


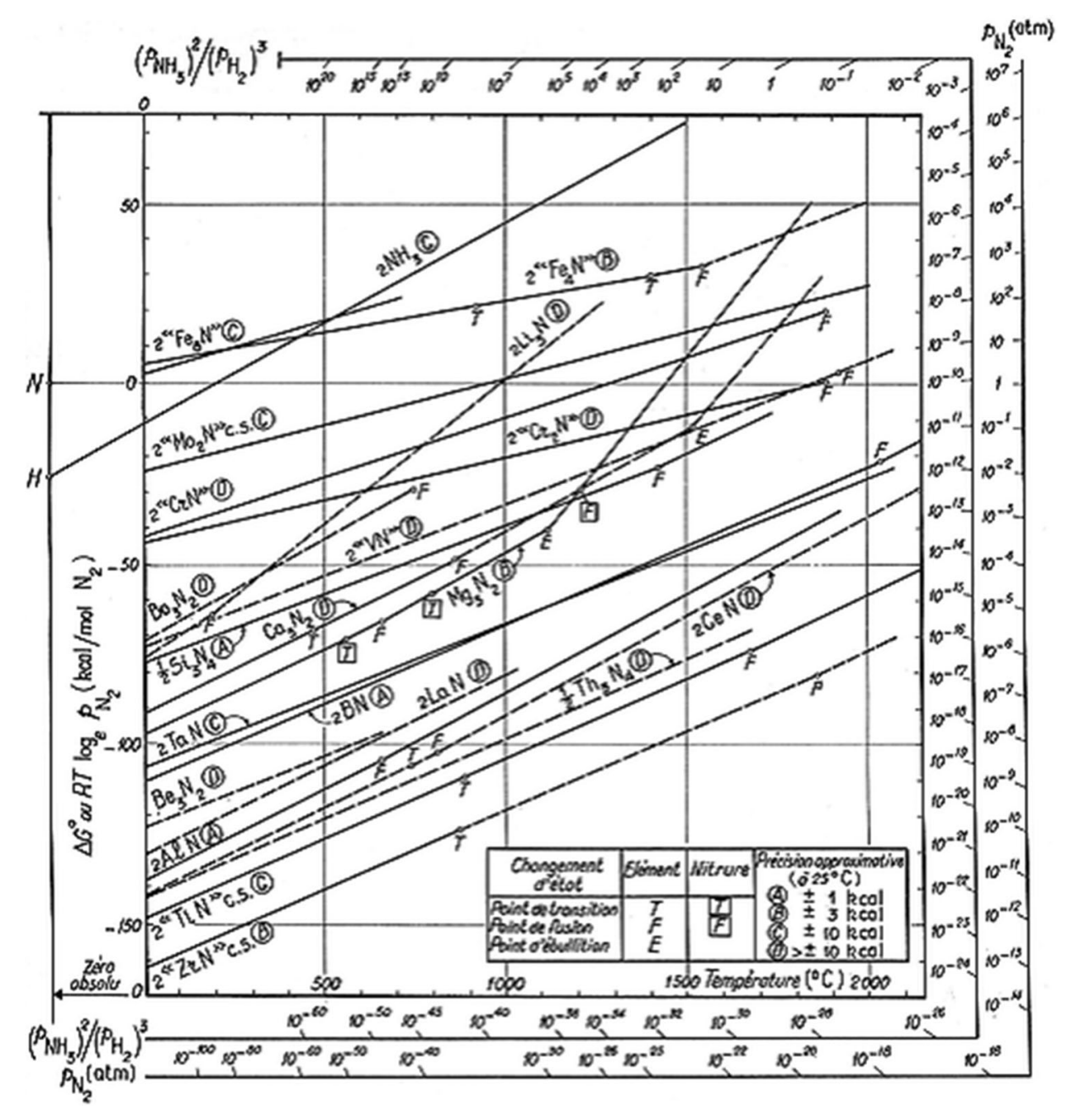

Fig. 4 Nitrides formation Ellingham diagram. The figure was reproduced from Ref 7 courtesy of Editions T.I.

preliminary tests were done to quantify the measuring error of Brinell hardness, which is classically used for gray cast iron, and Rockwell hardness. In both methods, the hardness measurements generate some dispersion. In the case of Rockwell hardness, this dispersion is only due to measuring tools because the machine directly gives the hardness. In the case of Brinell hardness, the dispersion of the measuring tool still exists but an additional error due to the measure by the operator of the hardness test marks must be added. Finally, the hardness chosen was the Rockwell one because the error on the measures was lower due to the lack of operator's error. The results presented later will show that the hardness variation during the aging will not be observable with Brinell hardness because this evolution belongs to the measuring error, contrary to the Rockwell hardness. At the end, the last parameters chosen were the diameter of the penetrator and the load to be able to follow the aging. For this, a nonnormalized hardness was finally selected using an indentor's diameter of $1 / 8$ inch and a load of 2500 N. Moreover, the choice of using a nonnormalized Rockwell hardness was made because the standard Rockwell hardness, like HRB, was not suitable for this study. The measurement of this particular Rockwell hardness, especially developed for this study, was able to follow the aging by giving hardness value in the Rockwell scale with enough allowance to observe the gain of hardness and by minimizing the measuring error. This particular Rockwell hardness will be called HR-AM (AM for Aging Monitoring) and used in the next parts of this article.

The last step before starting to follow the aging by hardness measurement was to characterize the accuracy and the repeatability of this measuring tool. The accuracy of this hardness was not possible to measure because standard sample for this nonnormalized hardness do not exist. The repeatability was measured by indenting 200 times the same sample of $35 \mathrm{CrMo} 4$ steel quenched and tempered to obtain a homogeneous martensitic structure. Finally, the results gave a low standard deviation of 0.7 point: this value is considered as the accuracy of this measuring tool.

To end with the part dealing about Rockwell hardness, all the casted samples measured by Rockwell hardness in this study were surfaced before monitoring, just to remove their skin (depth of cut $\approx 1 \mathrm{~mm}$ ). This step was necessary to observe the gain of hardness in the bulk material and remove the surface of the samples that could affect the hardness measures. The thickness removed by turning is about $1 \mathrm{~mm}$. Finally, the microstructure of the cast iron analyzed during this 

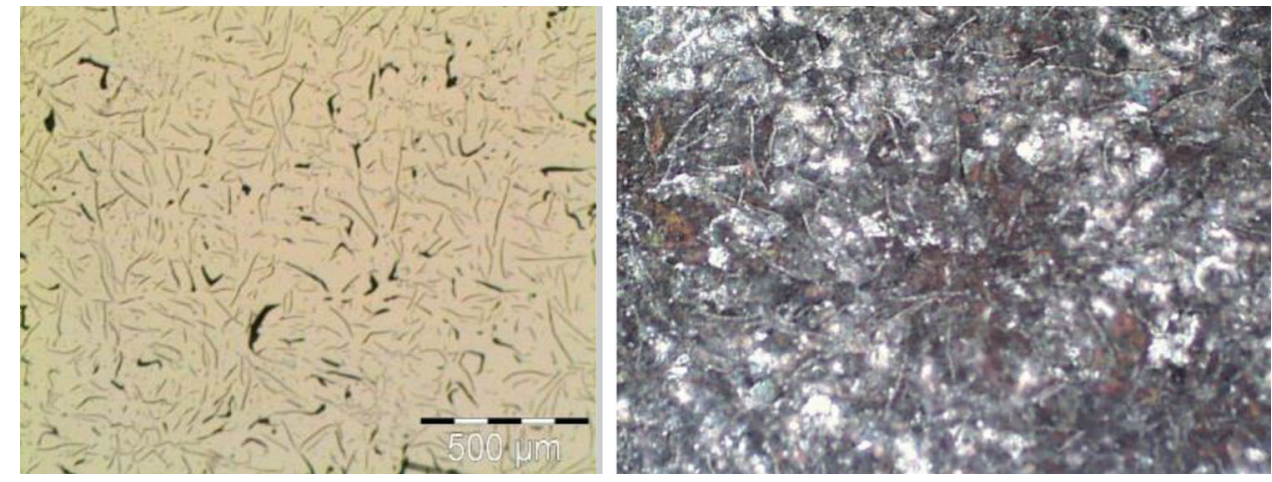

Fig. 5 Microstructure of casted iron samples analyzed without etching and with nital $4 \%$ etching

study is a classical matrix principally composed by pearlite with flake graphite I-A4/5 according to the standard ISO 945-1. This structure is visible in Fig. 5.

\subsection{Inherent Frequencies}

Richards and Nicola studies have shown that age strengthening increases mechanical properties (Ref 1, 2). Regarding that, Young's modulus of the material also should rise. To verify this hypothesis, it has been decided to follow the evolution of Young's modulus by measuring the inherent frequencies during aging with a free system. The natural frequencies, measured in a free system, are directly correlated with Young's modulus: $\omega_{0}^{2}=\alpha E$ with $\alpha$ representing a constant coefficient, which is different for each inherent frequency. This constant coefficient $\alpha$ was not determined in this study. Nevertheless, the determination of $\alpha$ was useless because it has no influence on the Eq 2. If cast iron Young's modulus increases during aging, as supposed, the value of each inherent frequency will also change. Therefore, it could be possible to follow age strengthening by measuring the shift of each frequency and thus calculate the gain of Young's modulus:

$E_{t}=E_{0}\left(\frac{\omega_{n t}^{2}}{\omega_{n 0}^{2}}\right)$

with 0 : nonaging state and $t$ : $t$-day aging state.

As done with Rockwell hardness, it was necessary to determine the measurement dispersion of this system. To find it, 20 natural frequency measurements have been done on a 30 day aged material to be sure of this stability. Finally, the maximal dispersion measured on a part was $0.8 \mathrm{~Hz}$, so it was decided to continue using this method considering it repeatable at $\pm 0.8 \mathrm{~Hz}$. Moreover, the frequency measurements have been made directly on raw parts.

\subsection{Alloying Elements Procedure}

As said by Richards (Ref 1,6) and Anish (Ref 9), alloying elements have an influence on age strengthening especially nitrogen and all the elements able to form nitrides before iron. The aim of this study is to show the effects of these elements. To do so, four different cast irons (EN GJL 200) were poured with the same cooling rate and variable free nitrogen content. Free nitrogen is defined as nitrogen in excess and able to react with iron and could be calculated in this study as (Ref 9):

$N_{\text {Free }}=N_{\text {Total }}-\frac{33}{100} \mathrm{Ti}$
The cast iron used in this study has just one element able to react with nitrogen before iron that is to say the titanium. The calculation of free nitrogen could be different in the presence of aluminum or zirconium in the alloy (Ref 9). The control of free nitrogen was done by addition of:

- High-purity FeTi (Ti $=40$ wt.\%, $\mathrm{C}<100$ ppm, $\mathrm{N}<150 \mathrm{ppm}, \mathrm{Fe}=$ balance) directly in furnace during the melting. The additive efficiency of FeTi in cast iron reaches $75 \%$.

- FeMnN obtained by nitriding ( $=5$ wt. $\%, \quad \mathrm{Mn}=75$ wt. $\%, \mathrm{C}<200 \mathrm{ppm}, \mathrm{Fe}=$ balance $)$ in ladle just before casting. The additive efficiency of FeMnN in cast iron is quite low, approximatively $30 \%$. The amount of titanium was measured by spark spectrometry. The nitrogen amount was given by reduction melting using an oxygen/ nitrogen analyzer. Table 1 presents the chemical composition of each cast iron poured for this project. The quantities of FeTi and FeMnN added for melting $125 \mathrm{~kg}$ of cast iron (capacity of the furnace) of each sample are also given in Table 1. Sample 2 is considered as the reference in this study because any addition of nitrogen or titanium was done for this cast iron.

The rates of free nitrogen were defined to have the largest range of variation. The principal issue of adding nitrogen in cast iron is the formation of porosities for amount higher than $100 \mathrm{ppm}$. So the higher free nitrogen content possible in this study due to the addition of nitrogen and the residual amount of titanium was reached for sample 4 .

\section{Results and Discussion}

As said, the aim of this study was to monitor the aging by nondestructive methods and identify the parameters responsive of the phenomenon and their respective influence. The paragraph will present the efficiency of the methods of monitoring described previously and shows the influence of alloying elements on the age strengthening.

\subsection{Monitoring of the Cast Iron Age Strengthening}

The first step was the experimental validation of age strengthening monitoring. The aim was to observe and quantify cast iron aging's intensity and time with Rockwell hardness and 
Table 1 Chemical composition of casted sample

\begin{tabular}{lccccccccc}
\hline & C, $\%$ & Si, \% & Mn, \% & S, \% & N, \% & FeMnN added, $\mathbf{g}$ & Ti, ppm & FeTi added, g & Free nitrogen \\
\hline Sample 1 & 3.37 & 1.79 & 0.55 & 0.065 & 49 & 0 & 160 & 65 \\
Sample 2 & 3.44 & 1.75 & 0.51 & 0.07 & 52 & 0 & 50 & 0 \\
Sample 3 & 3.42 & 1.81 & 0.98 & 0.069 & 101 & 890 & 150 & 60 \\
Sample 4 & 3.45 & 1.76 & 0.95 & 0.072 & 99 & 880 & 50 & 0 & 33.5 \\
\hline
\end{tabular}

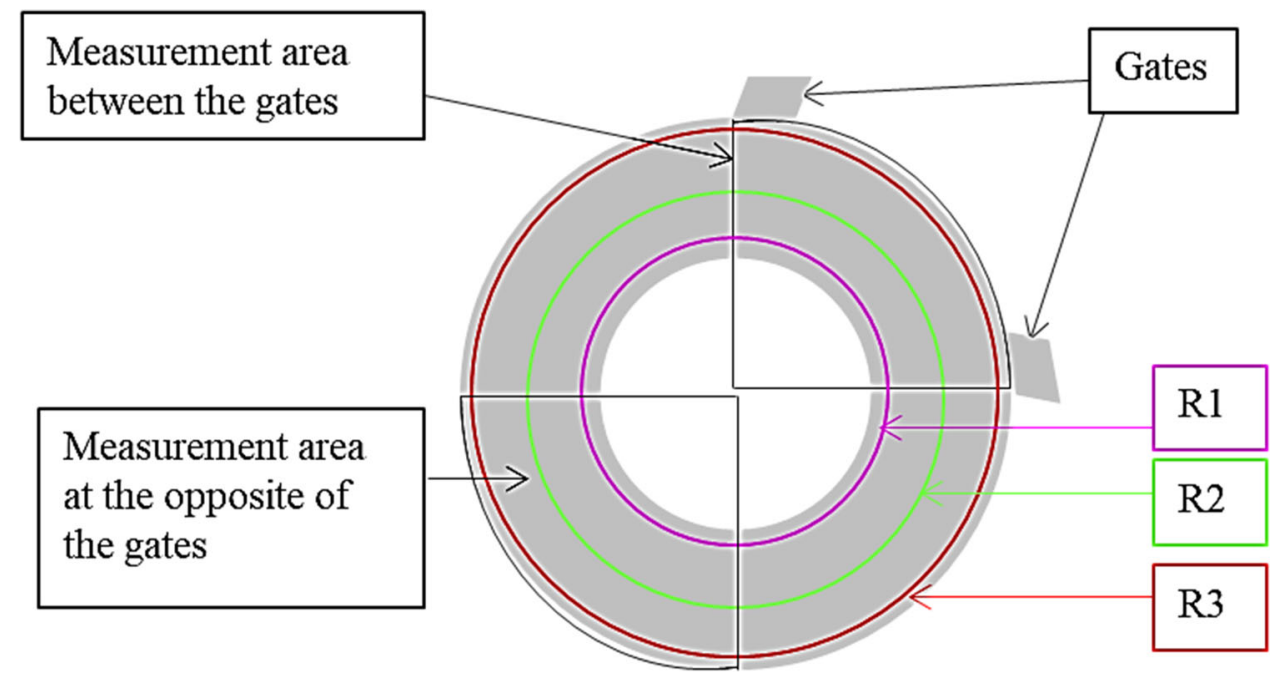

Fig. 6 Hardness measurements areas

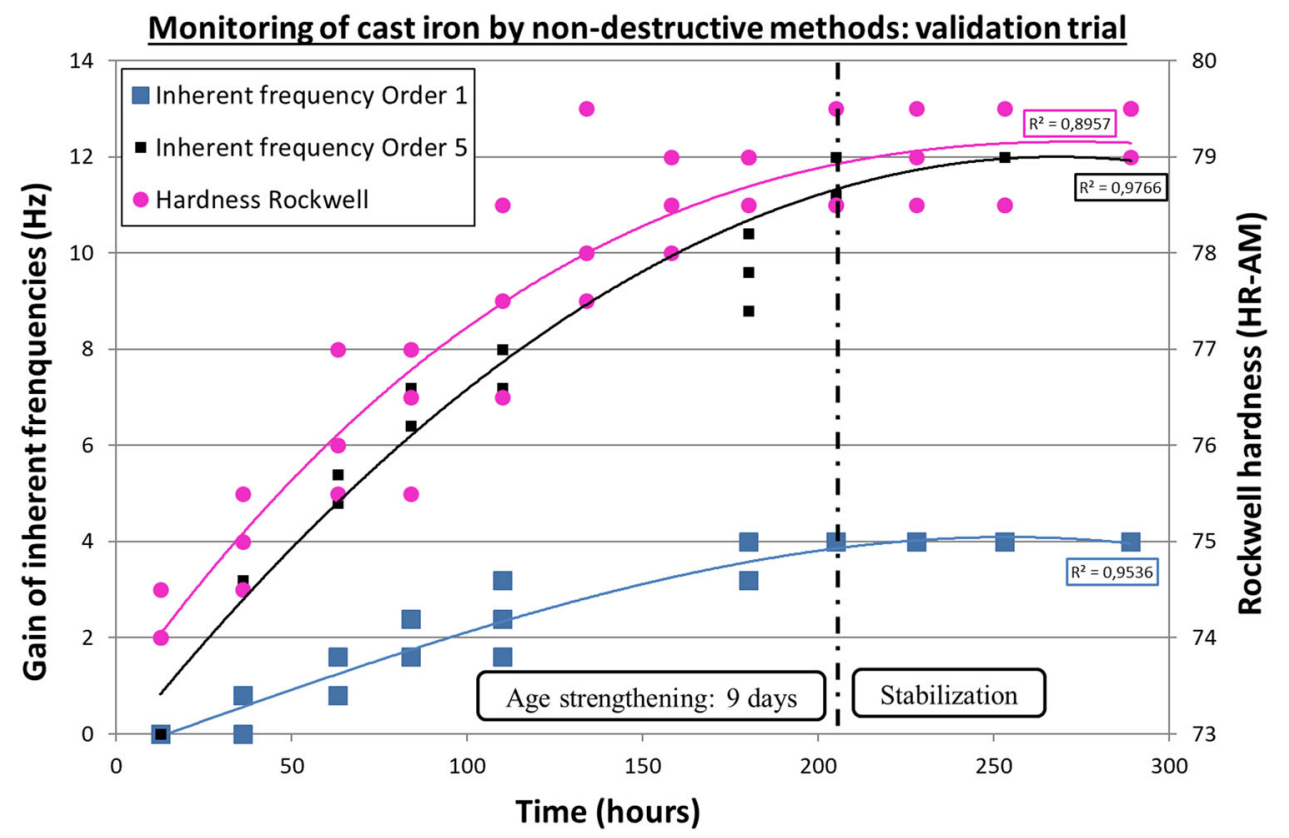

Fig. 7 Correlation of the different methods of monitoring

inherent frequencies. In agreement with Renault, the cast iron parts were poured directly in laboratory to minimize the time between the monitoring of the aging and the casting. Obviously, the laboratory parts need to represent as well as possible the industrial one. That is why their chemical composition and cooling rate were kept. The control of the part's cooling rate was done with the mold opening temperature. The temperature of $450{ }^{\circ} \mathrm{C}$ was chosen to be the most representative as possible of industrial process.

For this trial of validation, three measures of hardness and natural frequency were done daily during 2 weeks to monitor the aging at room temperature. Figure 7 shows the results. Each 
point of the curves represents a measure, not an average value. Concerning the hardness, the measurements were done in two different areas of the parts visible in Fig. 6: near the gate and at the opposite. In these areas, the parts were indented at three different radiuses. To be clearer, only the results of the hardness taken on radius $\mathrm{R} 1$ in the area located at the opposite of the gates are presented in Fig. 7. The other hardness measurements follow the same evolution. Finally, concerning the inherent frequencies, the order 1 to 5 natural frequencies has been monitored. Just like hardness, only the inherent frequencies of order 1 and 5 are visible in Fig. 7.

First of all, the monitoring of the cast iron age strengthening with two different methods presents the same results. So the evolution of hardness and inherent frequencies is the same during the aging. Moreover, this evolution seems to be the same as the one observed by Richard and Nicola using tensile test (Ref 1). The results show an increase in the hardness and an evolution of the value of each inherent frequency during $120 \mathrm{~h}$ followed by a stabilization phase. An additional time of $5 \mathrm{~h}$ needs to be added at the $120 \mathrm{~h}$ of aging for the preparation of the parts before the measurements. Finally, this trial of validation gave two main results:

- The monitoring of the aging using classical and nondestructive mechanical tests seems to be possible. The results of the two methods used are in accordance with the literature review.

- Renault's cast iron had an aging time of nearly $125 \mathrm{~h}$. This time is in accordance with observations made on the industrial process concerning the 7-days lapse before machining the break disks for having a better metallurgical stability.

\subsection{Influence of Alloying Elements on Age Strengthening}

After proving the efficiency of monitoring methods, all the casted samples presented in Table 1 were monitored using these two different methods. Table 2 summarizes all these results. Figure 8 and 9 show the results of the age strengthening monitoring of each sample:

First, it is possible to see, with both monitoring methods, that the time for aging to complete increases with the amount of free nitrogen. As expected, the time of nitrogen diffusion and so of iron-nitride formation rised with free nitrogen. In the same way, the gain of mechanical properties, hardness and Young's modulus follows the same evolution that the aging time. Moreover, this evolution is in accordance with the literature

Table 2 Age strengthening monitoring results

\begin{tabular}{lllll}
\hline & S1 & S2 & S3 & S4 \\
\hline $\mathrm{N}_{\text {Free, ppm }}$ & 0 & 33.5 & 51.5 & 82.5 \\
Aging time, h & 0 & 150 & 180 & 230 \\
Hardness gain, HR-AM & 0 & 3.5 & 5 & 7.5 \\
Young's modulus gain, GPa & 0 & 0.8 & 1 & 1.4 \\
Frequency shift, Hz & 0 & 13 & 15 & 21 \\
\hline
\end{tabular}

review (Ref 1). Nevertheless, Fig. 7, 8 and 9 show a logarithmic evolution of mechanical properties contrary to sigmoid evolutions visible in the literature (Ref $1,2,5)$. The difference could be explained by the fact that only the age strengthening period, when mechanical properties start changing until they reach stability, had been studied and not the incubation period corresponding to the nitrogen diffusion time. The aim of this study was finding nondestructive methods to observe and evaluate the duration and the intensity of gray cast iron. It is why the time before age strengthening, when mechanical properties do not evolve, was not reported in this study. Nevertheless, the delay caused by an excessive amount of manganese in cast iron on age strengthening had also been observed as Richards and Teague (Ref 1, 2, 10).

These methods of age strengthening monitoring showed the instability of cast iron just after casting and especially just before machining. This modification of the mechanical properties explains the variation of machinability of casted parts in function of the aging time shown by Richards (Ref 1), Teague (Ref 2) and another study led in LaBoMaP.

Then, this study shows that it is possible to control cast iron age strengthening using alloy elements during the melting. Controlling free nitrogen amount in cast iron is the more effective way to control aging time and intensity (Ref 10). In the case of the Sample 2, age strengthening had been annihilated by titanium addition. Nevertheless, regarding the price of alloying elements, this solution of aging control by driving free nitrogen amount seems to be not effective in industrial conditions.

Finally, these methods of monitoring could allow determining a model of aging time and intensity of cast iron in function of free nitrogen amount for this cast iron with this cooling rate. The cast iron cooling rate has also an influence on age strengthening, but it is a second-order parameter in comparison with the chemical composition (Ref 10). Figure 10 shows the prediction model obtained during this study. In addition, the equations below predict the aging time, the hardness gain and the Young's modulus gain in function of free nitrogen amount of the cast iron studied.

$$
\begin{aligned}
& \Delta_{\text {Hardness }}=0.095 * \mathrm{~N}_{\text {Free }}-0.22: \text { in } \mathrm{HR}-\mathrm{AM} \\
& \Delta_{E \text { (Young Modulus })}=0.017 * \mathrm{~N}_{\text {Free }}+0.12: \text { in } \mathrm{GPa} \\
& t_{\text {aging }}=2.71 * N_{\text {Free }}+2.65: \text { in hour }
\end{aligned}
$$

A general model describing age strengthening could be possible with these methods. The actual model needs to be enhanced by monitoring different cast irons. Indeed, the chemical composition of cast iron is the first-order parameter on the aging and especially the following elements:

- All the elements are more reactive with nitrogen than iron as aluminum or zirconium for example. These elements could be found using Ellingham diagram in Fig. 4 (Ref 7). The amount of those elements could modify the calculation of free nitrogen rate.

- Carbon and silicon because of the solubility of nitrogen in cast iron are directly correlated with the amount of those elements (Ref 6). 


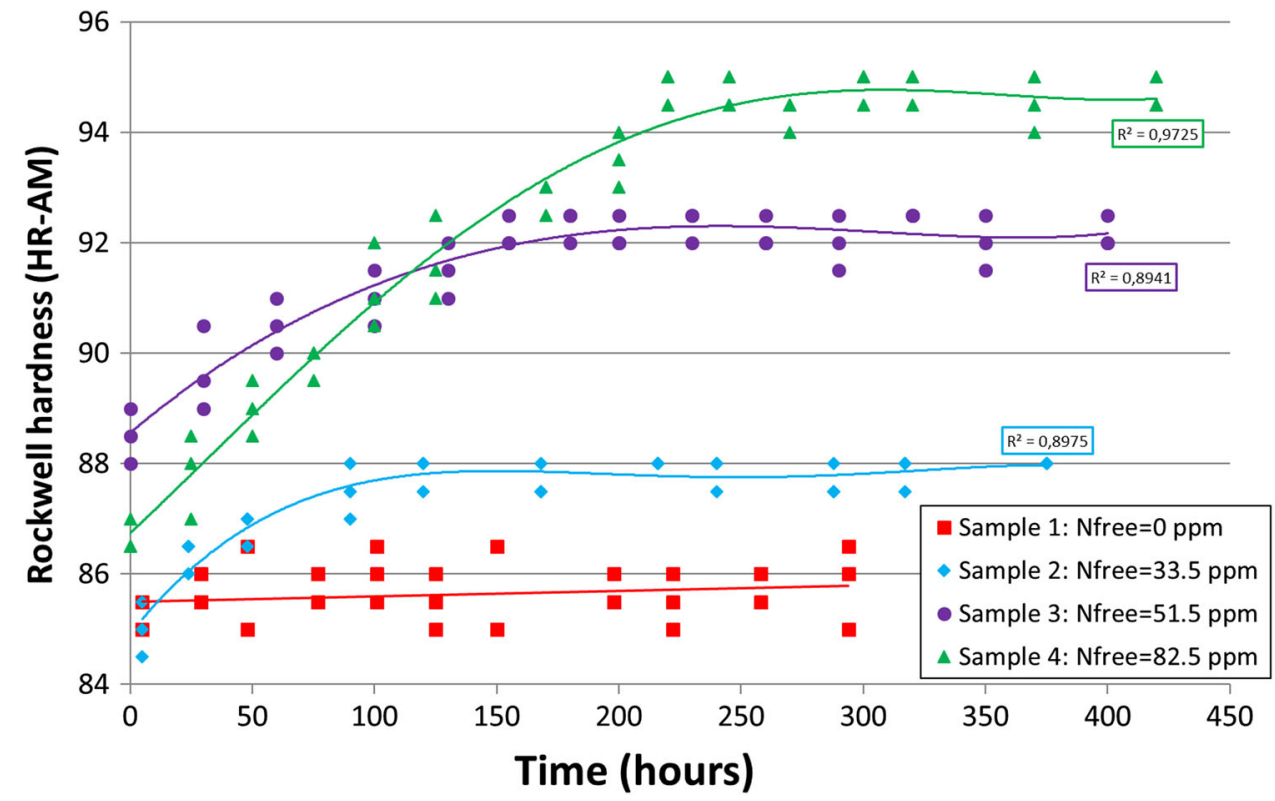

Fig. 8 Influence of free nitrogen on age strengthening: hardness monitoring

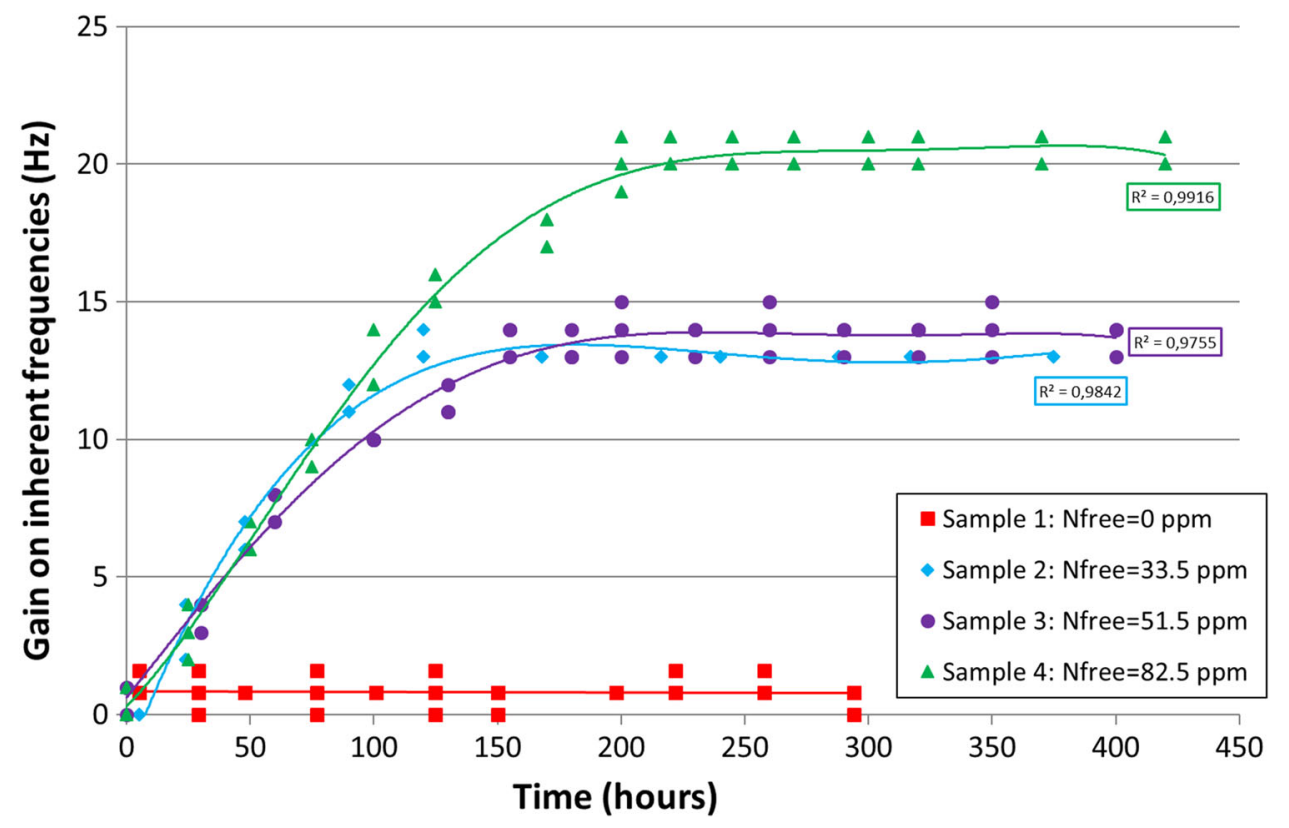

Fig. 9 Influence of free nitrogen on age strengthening: inherent frequencies monitoring

\section{Conclusions}

The study shows the possibility to monitor cast iron age strengthening by nondestructive methods like Rockwell hardness and inherent frequencies measurements. This allows following this phenomenon directly on industrial parts with a little preparation of samples. These types of monitoring could be useful in industrial conditions to guarantee the metallurgical stability of parts before machining.

Then, the effects of alloying elements on age strengthening had been shown. Cast iron aging could be controlled by addition of different elements. This control must be done by the regulation of free nitrogen amount cast iron using for example titanium, aluminum or zirconium. Nevertheless, the annihilation of this phenomenon by extra addition during melting could not be viable regarding the cost of raw materials in comparison with stocking the parts for a few days.

Finally, a prediction model of age strengthening had been proposed for the cast iron studied. This model is valid only in the conditions of this study. Not all the alloying elements able to affect this phenomenon were studied, and so their effects on the aging could not be estimated accurately. This work could be followed by monitoring different cast irons to enhance the model in order to take into account the influence of the carbon or of the cooling rate for example. 


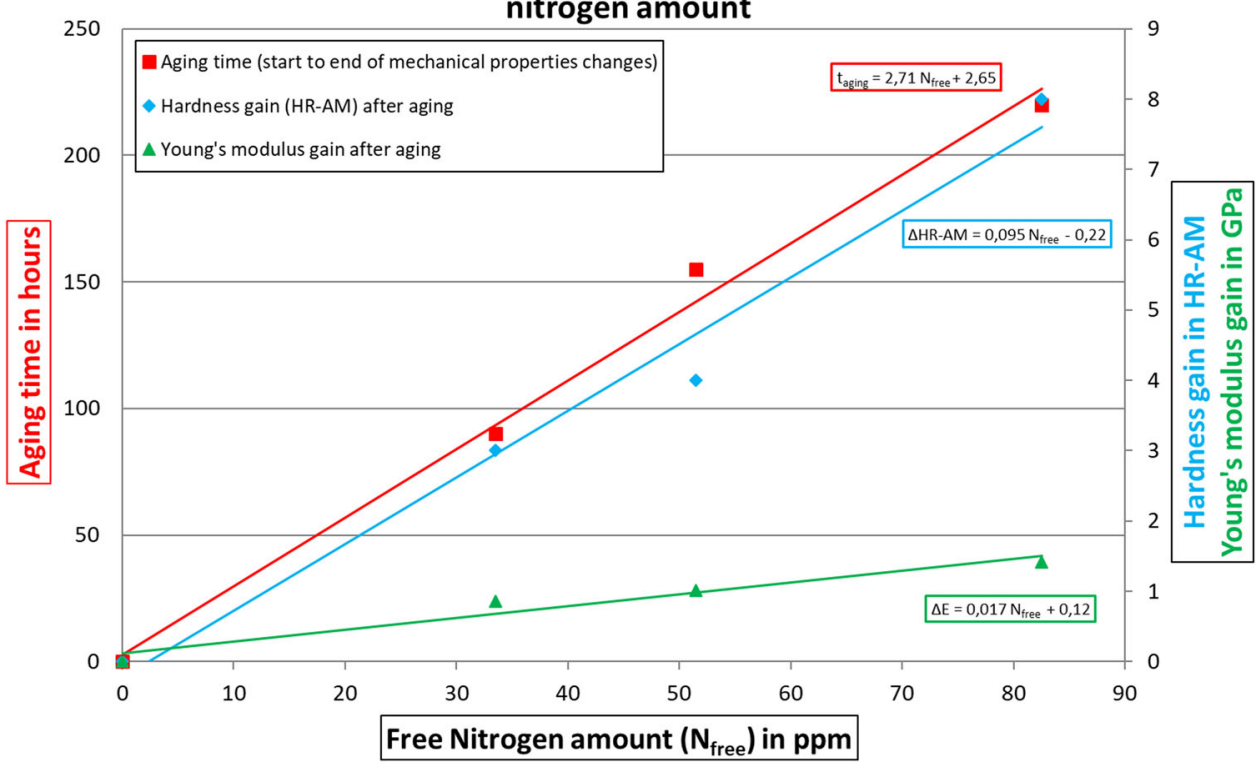

Fig. 10 Prediction model of cast iron age strengthening as a function of free nitrogen amount. The model is a linear regression of the different results obtained by monitoring cast iron aging

\section{Acknowledgments}

This study was financially supported by Renault Le Mans. This work was carried out as a part of a PhD thesis No 2012-ENAM-0016.

\section{References}

1. V. Richards and W. Nicola, Age Strengthening of Gray Cast Iron Phase III, Int. J. Cast Met. Res., 2003, 16(1-3), p 275-280

2. J. Teague, Dependency of Machinability in Gray Cast Iron on NitrideInduced Age Strengthening, Doctoral dissertations, Missouri University of Science and Technology, 2010

3. V. Richards, T. Anish, S. Lekakhet et al., Age Strengthening of Gray Iron-Kinetics Study, Int. J. Metalcast. (IJMC), 2008, 2(1), p 7-16

4. P.B. Burgess, Age Hardening Ferritic Malleable, AFS Tran., 1969, 56, p 172-179

5. J. Teague and V. Richards, Age Strengthening of Cast Irons: Review of Research and Literature, Int. J. Metalcast., 2010, 4(2), p 45-57
6. V. Richards, T.V. Anish, S. Lekakh, D.C. Van Aken, W. Nicola, Composition Effects on Age Strengthening of Gray Iron, University of Missouri-Rolla, 2006

7. C. Gatellier, P.V. Riboud, A. Rist, and M.F. Ancey-Moret, Equilibres thermodynamiques en sidérurgie (Thermodynamic Equilibriun in the Iron and Steel Industry), Techniques de l'ingénieur, Dossier M 1730, 1974 (in French)

8. Casting Plant and Technology International, Improving the Mechanical Properties of Grey Cast Iron by Alloying with Nitrogen, 2009, $\mathrm{N}^{\circ} 1$

9. T.V. Anish, Age Strengthening of Gray Cast Iron: Alloying Effects and Kinetics Study, Masters Theses, 4554, 2007

10. A. Vaucheret, Etude du vieillissement des fontes à graphite lamellaire en vue de l'amélioration de leur usinabilité, Ph.D. Thesis, 2012 (in French)

Publisher's Note Springer Nature remains neutral with regard to jurisdictional claims in published maps and institutional affiliations. 